\title{
Pattern of psychiatric illnesses among long-stay patients at Mental Health Hospital, Taif, Saudi Arabia: a 10-year retrospective study
}

H. Al-Zahrani, ${ }^{1}$ A. Al-Qarni ${ }^{1}$ and M. Abdel-Fattah ${ }^{2}$

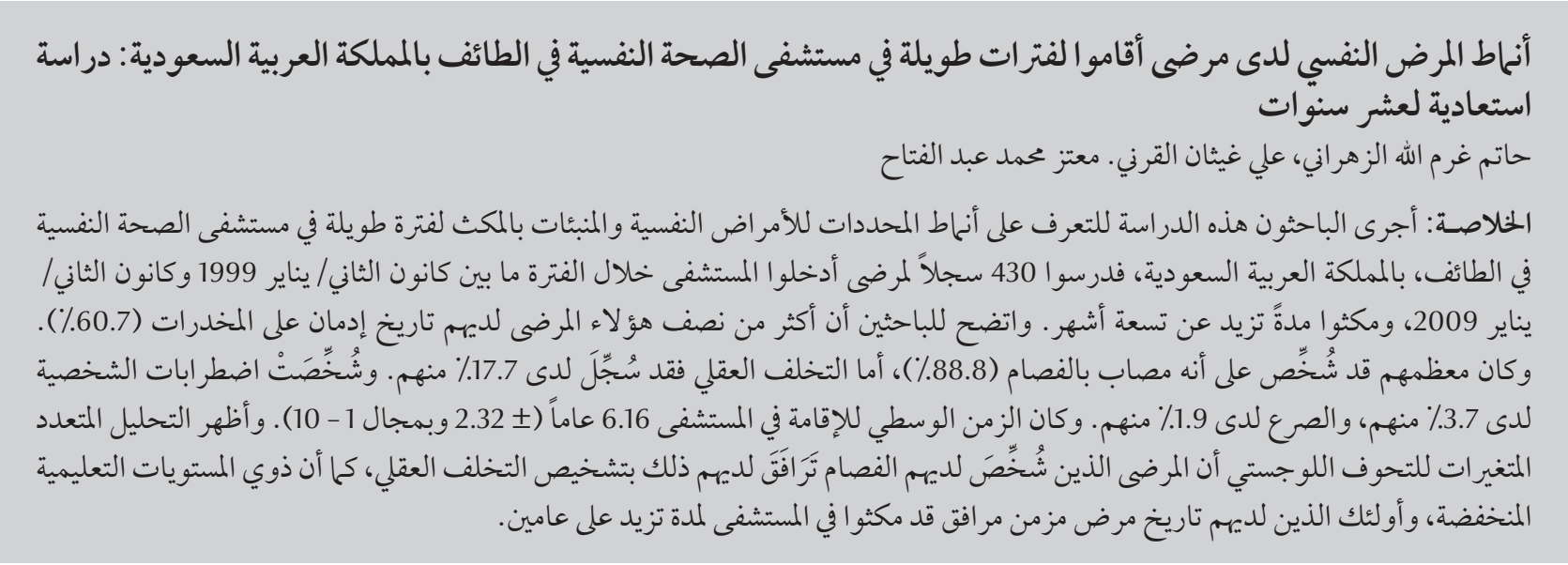

ABSTRACT To identify the pattern and determinants of psychiatric illness and the predictors of long stay among long-stay patients at the Mental Health Hospital, Taif, Saudi Arabia, we examinede a total of 430 records of patients who had been admitted during the period January 1999-January 2009 and had stayed for $>9$ months. More than half these patients had a history of drug addiction (60.7\%). The majority were diagnosed with schizophrenia (88.8\%) and mental retardation was reported in $17.7 \%$. Personality disorders and epilepsy were diagnosed in $3.7 \%$ and $1.9 \%$ of the participants respectively. The mean duration of hospital stay was 6.16 (standard deviation 2.32; range 1-10) years. Multivariate logistic regression analysis showed that patients diagnosed with schizophrenia accompanied by mental retardation, those with lower education levels, and those with a history of co-morbid chronic diseases stayed for more than 2 years.

Profil des troubles psychiatriques chez des patients en séjour de longue durée à l'hôpital psychiatrique de Taïf (Arabie saoudite) : étude rétrospective sur dix ans

RÉSUMÉAfin d'identifierle profil etles déterminants des troubles psychiatriques etles facteurs prédictifs d'un séjour delongue durée chez des patients en séjourdelongue duréeàl'hôpital psychiatrique deTaïf(Arabie saoudite), nous avons examiné au total 430 dossiers de patients qui avaient été admis entre janvier 1999 et janvier 2009 et dont le séjour avait duré plus de neuf mois. Plus de la moitié de ces patients avait des antécédents de toxicomanie (60,7 \%). La majorité a reçu le diagnostic de schizophrénie (88,8 \%) et une arriération mentale a été observée dans $17,7 \%$ des cas. Le diagnostic de troubles de la personnalité et d'épilepsie a été posé chez 3,7 \% et 1,9\% des participants, respectivement. La durée moyenne du séjour en établissement hospitalier était de 6,16 ans (écart type 2,32 ; extrêmes 1-10 ans). L'analyse de régression logistique multivariée a démontré que les patients ayant reçu le diagnostic de schizophrénie associée à une arriération mentale, les patients ayant un niveau d'études plus faible, et ceux ayant des antécédents de comorbidités chroniques y séjournaient plus de deux ans. 


\section{Introduction}

Serious and persistent mental illnesses can result in considerable functional impairment requiring long-term hospitalization. Most patients requiring institutional care of extended duration have limited functional capacity in relation to a number of primary aspects of daily life, including personal hygiene and self-care, self direction, interpersonal relationships, social transactions, learning and recreation [1].

The deleterious influence of traditional custodial care on the long-stay population of mental hospitals has been well-documented [2]. The last $2 \mathrm{dec}$ ades have witnessed a major shift in the provision of psychiatric services to the acutely disturbed patients in general, and to the chronically disabled group of patients in particular. Increasingly, patients are living in the community, and the number of mental hospital beds has correspondingly decreased. In the United Kingdom for instance, 38 (29\%) of 130 hospitals with more than 100 beds were closed between 1980 and 1993 [3] while in the United States of America 65 (20\%) of 321 state hospitals were closed between 1972 and 1993 [4]. Whereas "too rapid" a shift from hospital-based to community-based care has proved counterproductive in some cases [5], most workers have found it to encompass greater potential for stabilization, and even improvement, of the condition of long term psychiatric patients. In addition, community-based care has been shown to be cost effective. In a 3-year follow-up study of 321 discharged state hospital patients in the United States of America, the cost of community care was lower than the estimated cost of state hospitalization [6]. Similar findings have been reported by other researchers $[7,8]$.

Estimates vary as to how many longstay psychiatric patients could possibly be discharged into the community. Obviously, it depends on the nature of their illness and the degree of functional deficits of the patients as well as the availability of suitable accommodation and activity programmes in the community. In a national sample survey of 15 mental hospitals in England and Wales, about one-third needed further hospital care, one-third were suitable for discharge into the community, and the remaining third, because they had multiple handicaps (including physical disability and mental retardation), were in hospital simply because no other agency would accept them [9].

Chronic psychiatric conditions are emerging challenges facing both developing and industrialized nations [10]. Despite the growing awareness of the public, and health and education professionals regarding the economic, psychological and medical impact of mental illnesses, limited research has been carried out to determine the pattern of mental disorders in Saudi Arabia $[11,12]$. Perhaps the most important obstacle in implementing intervention programmes is the lack of appropriate epidemiological research on the general population. Moreover, the appropriateness of the official mental statistics for determining the level of care needed by psychiatric patients is a controversial issue and therefore needs to be emphasized more [13]. In addition, many people with psychiatric conditions require continuous health care, home help and other supportive services, including substantial medical, educational, social and rehabilitative care, which makes care programmes very costly.

Most of the studies designed to assess the population profile of psychiatric institutions and the deinstitutionalization process were carried out in industrialized countries. Little is known about these institutions and their residents in Saudi Arabia. There are number of difficulties associated with conducting research on psychiatric related issues in Saudi Arabia. Some of these difficulties are related to the characteristics of Saudi Arabian society, e.g. some families feel ashamed about having a family member with a psychiatric illness and as a result, tend to avoid participation in such research. Saudi society's view of people with psychiatric disorders is based on a simple notion of disability; this includes helplessness, continuing dependence, being home-bound, low quality of life, lack of productivity [12] and for mental illnesses, being a danger to others

Hospital- and community-based research to determine the pattern of psychiatric disorders could contribute to information about prevalence, type and distribution of mental disorders in Saudi Arabia. It will also provide information for health planning and policies addressing the needs of such special group of people. The present study was conducted to identify the pattern and determinants of psychiatric disorders among long-stay patients in Taif Mental Health Hospital.

\section{Methods}

This study was conducted at the Ministry of Health Mental Health Hospital, Taif, Western Region, Saudi Arabia. This hospital has 690 beds, making it the biggest mental health hospital in the country. It has forensic psychiatric wards and outpatient clinics. Patients are referred from all over the country, and all types of psychiatric disorder are accepted, including schizophrenia, epilepsy, mental subnormality, affective disorders, personality disorders, drug addiction.

We carried out this retrospective cohort study during 2010, reviewing the records of patients with mental health disorders who stayed in the hospital for more than 9 months (long stay), according to the classification of Gath, Hassall and Cross [14]. Records for patients diagnosed during the 10-year period January 1999-January 2009 were included in the study. Length of stay was calculated from the date of admission to the date of discharge [14]. 
Medical records were reviewed and comparisons made regarding medical status, sociodemographic data and duration of hospitalization. Patients were categorized according to their diagnosis.

The total number of patients admitted during the study period was 11310 , and the estimated number of long stay (>9 months) patients was 430 .

\section{Data collection}

A checklist was designed to include demographic and personal predictors (age, sex, nationality, education, marital status, occupation); and medical predictors (date of admission, date of discharge, reason for discharge, diagnosis, any associated co-morbidities). Sampling of patients' records was reviewed to ensure the availability of all data included in the checklist. Diagnosis was made using DSM IV criteria [15]. The diagnosis was confirmed by a team comprising 1 psychiatric consultant and two family medicine consultants.

Approval for this research was obtained from the research and ethics committee at Taif Armed Forces Hospital. We also obtained approval from the administration at Taif Mental Health Hospital to access patient records.

\section{Statistical analysis}

We used SPSS, version 16.0, for data entry and analysis. Descriptive statistics [e.g. number, percentage, range, standard deviation (SD), arithmetic mean] and analytic statistics using chi squared to test for the association between 2 categorical variables were applied.

The duration of hospital stay was divided into 2 categories: those who had stayed $\leq 2$ years and those who had stayed $>2$ years. We excluded those patients admitted after $2008(n=31)$. Hospital stay was treated as a dependent variable in multivariate logistic regression analysis. Age, sex, marital status, education level, work status, housing, salary, smoking status, drug addiction, reason for long hospital stay, diagnosis and co-morbid diseases were treated as independent categorical variables.

Multiple associations were evaluated in the multiple logistic regression model, based on backward stepwise selection where significant variables from the univariate analysis were included. This allowed the estimation of the strength of the association between each independent variable while taking into account the potential confounding effects of the other independent variables. The covariates were removed from the model if the likelihood ratio, based on the maximum likelihood estimates, had a probability of $>0.10$. Each category of predictor variables was contrasted with the reference category. The adjusted measure of association between risk factor and depression was expressed as odds ratio (OR) with 95\% confidence interval (CI). Adjusted or crude OR with 95\% CI that did not include 1.0 was considered significant.

\section{Results}

\section{Sociodemographic characteristics}

A total of 430 records of patients who were admitted to Taif Mental Hospital during the period January 1999-January 2009 were reviewed to identify the pattern of psychiatric illnesses and to determine predictors of long stay at the hospital. Age ranged between 23 and 77 years, with a mean of 44.08 (SD 7.80 ) years (Table 1 ). There were 386 males (89.8\%) and only 44 females. All patients were Saudi Arabian, most of them from the Western Region (76\%). Most of the patients in the study were single $(66.5 \%)$. The majority were not working (88.4\%). None were educated above secondary school level.

\section{Smoking and addiction history}

Only $19.5 \%$ of the studied patients were non-smokers and $38.2 \%$ were exsmokers (Table 1). More than half had history of drug addiction (60.7\%).
The majority of patients were diagnosed with schizophrenia (88.8\%). Mental retardation was reported in $17.7 \%$ of the participants, personality disorders in $3.7 \%$ and epilepsy in $1.9 \%$. History of co-morbidity was reported among 88 patients (20.5\%): diabetes mellitus was reported in 39 (44.3\%) cases and hypertension in 37 (42.0\%), while heart disease was reported in only 12 cases (13.6\%).

Schizophrenia was significantly associated with smoking status $(P<$ $0.001)$ (Table 2). The vast majority of the patients with schizophrenia were either smokers or ex-smokers (83.7\%) compared to $54.2 \%$ among nonschizophrenic patients. Almost twothirds of patients with schizophrenia had a positive history of drug addiction compared with just under one-third of non-schizophrenic patients. The difference was statistically significant $(P<$ 0.001) (Table 2).

\section{Duration and determinants of duration of hospital stay}

The mean duration of hospital stay was 6.16 (SD 2.32) years with a range of $1-10$ years and a median of 6 years. Older patients were more likely to have a longer hospital stay ( $>2$ years): just over two-thirds of those in the age groups $41-50$ years and $58.5 \%$ of those $>50$ years stayed in hospital more than 2 years compared with only $47.7 \%$ of patients in the age group $\leq 40$ years (Table 3). Males tended to stay in the hospital longer than female patients, but the difference was not statistically significant $(P=0.109)$. More than half the patients with lower levels of education stayed more than 2 years in the psychiatric hospital compared with $34.3 \%$ of those who were educated to secondary school level (Table 3). The difference was statistically significant.

Patients whose families refused to take them back were about 2 times as likely to have a longer stay than those who stayed on the orders of highranking officials (this was, however, 


\begin{tabular}{|c|c|c|}
\hline Characteristic & No. & $\%$ \\
\hline \multicolumn{3}{|l|}{ Age (years) } \\
\hline$\leq 40$ & 132 & 30.7 \\
\hline $41-50$ & 232 & 54.0 \\
\hline$>50$ & 66 & 15.3 \\
\hline Range & \multicolumn{2}{|c|}{$23-77$} \\
\hline Mean (SD) & \multicolumn{2}{|c|}{$44.08(7.80)$} \\
\hline \multicolumn{3}{|l|}{ Sex } \\
\hline Male & 386 & 89.8 \\
\hline Female & 44 & 10.2 \\
\hline \multicolumn{3}{|l|}{ Residence } \\
\hline Western Region & 327 & 76.0 \\
\hline Central Region & 62 & 14.5 \\
\hline South Region & 25 & 5.8 \\
\hline North Region & 10 & 2.3 \\
\hline Eastern Region & 6 & 1.4 \\
\hline \multicolumn{3}{|l|}{ Marital status } \\
\hline Single & 286 & 66.5 \\
\hline Divorced & 120 & 27.9 \\
\hline Married & 20 & 4.7 \\
\hline Widowed & 4 & 0.9 \\
\hline \multicolumn{3}{|l|}{ Education level } \\
\hline Illiterate or R\&W & 145 & 33.7 \\
\hline Primary schools & 143 & 33.3 \\
\hline Intermediate schools & 104 & 24.2 \\
\hline Secondary school & 38 & 8.8 \\
\hline \multicolumn{3}{|l|}{ Work status } \\
\hline Not working & 380 & 88.4 \\
\hline Working & 10 & 2.3 \\
\hline Retired & 40 & 9.3 \\
\hline \multicolumn{3}{|l|}{ Housing } \\
\hline Owned & 318 & 74.0 \\
\hline Rented & 112 & 26.0 \\
\hline \multicolumn{3}{|l|}{ Private income } \\
\hline No & 408 & 94.9 \\
\hline Yes & 22 & 5.1 \\
\hline \multicolumn{3}{|l|}{ Smoking status } \\
\hline Current smoker & 182 & 42.3 \\
\hline Ex-smoker & 164 & 38.2 \\
\hline Non-smoker & 84 & 19.5 \\
\hline \multicolumn{3}{|l|}{ History of drug addiction } \\
\hline Yes & 261 & 60.7 \\
\hline No & 169 & 39.3 \\
\hline
\end{tabular}

$S D=$ standard deviation

$R \& W=$ just able to read and write. usually at the request of the patient's close relatives) [odds ratio $(\mathrm{OR})=$ 2.02; $95 \%$ confidence interval (CI): $1.13-3.60]$.

Patients with a history of co-morbid chronic disease had an increased risk of long-hospital stay compared with patients with no history $(\mathrm{OR}=2.02$; 95\% CI: 1.19-3.46 (Table 3). Patients with a combined history of schizophrenia and mental retardation had a 9-fold risk compared with those with history of personality disorder $(\mathrm{OR}=9.0 ; 95 \%$ CI: 1.90-46.22)). Sex, marital status, work status, housing, salary, smoking status and history of drug addiction were not independently associated with long-stay at the hospital.

Longer stay was significantly associated with lower education level compared with secondary school education (Table 4). Patients diagnosed with schizophrenia and mental retardation were more likely to have stayed more than 2 years in hospital than those with personality disorder ( $\mathrm{OR}=7.02$; 95\% CI: 1.95-33.12). Patients with history of chronic comorbid disease had a 2 -fold risk compared with those with no history of chronic disease $(\mathrm{OR}=2.18$; 95\% CI: 1.47-4.13) (Table 4). Age and reason for long hospitalization were not independently associated with long hospital stay.

\section{Discussion}

This study focused on outlining the relationship between sociodemographic characteristics and clinical diagnosis of patients and length of stay in a psychiatric hospital.

In accordance our findings, in a study on long-stay patients in a psychiatric hospital in Southern Brazil, the demographic data of the study population mostly showed long hospital stay, high level of illiteracy and low education, poor engagement in occupational/job activities, and situations where familial 


\begin{tabular}{|c|c|c|c|c|c|c|}
\hline \multirow[t]{3}{*}{ Habit } & \multicolumn{4}{|c|}{ Schizophrenia } & \multirow[t]{3}{*}{$\chi^{2}$} & \multirow[t]{3}{*}{$P$-value } \\
\hline & \multicolumn{2}{|c|}{ Yes $(n=382)$} & \multicolumn{2}{|c|}{ No $(n=48)$} & & \\
\hline & No. & $\%$ & No. & $\%$ & & \\
\hline \multicolumn{7}{|l|}{ Smoking status } \\
\hline Current smoker & 164 & 42.9 & 18 & 37.5 & 25.96 & $<0.001^{*}$ \\
\hline Ex-smoker & 156 & 40.8 & 8 & 16.7 & & \\
\hline Non-smoker & 62 & 16.3 & 22 & 45.8 & & \\
\hline \multicolumn{7}{|l|}{ Addiction history } \\
\hline Yes & 247 & 64.7 & 14 & 29.2 & 22.52 & $<0.001^{*}$ \\
\hline No & 135 & 35.3 & 34 & 70.8 & & \\
\hline
\end{tabular}

*Statistically significant.

\begin{tabular}{|c|c|c|c|c|c|c|}
\hline \multirow[t]{3}{*}{ Determinant } & \multicolumn{4}{|c|}{ Duration of hospital stay } & \multirow[t]{3}{*}{ Crude OR } & \multirow[t]{3}{*}{$95 \% \mathrm{Cl}$} \\
\hline & \multicolumn{2}{|c|}{$\begin{array}{l}\leq 2 \text { years } \\
(n=214)\end{array}$} & \multicolumn{2}{|c|}{$\begin{array}{l}>2 \text { years } \\
(n=216)\end{array}$} & & \\
\hline & No. & $\%$ & No. & $\%$ & & \\
\hline \multicolumn{7}{|l|}{ Age (years) } \\
\hline$\leq 40^{\mathrm{a}}$ & 59 & 52.3 & 54 & 47.7 & 1.0 & \\
\hline $41-50$ & 73 & 33.1 & 148 & 66.9 & 2.22 & $1.36-3.62^{*}$ \\
\hline$>50$ & 27 & 41.5 & 38 & 58.5 & 1.54 & $0.79-2099$ \\
\hline \multicolumn{7}{|l|}{ Sex } \\
\hline Males $^{\mathrm{a}}$ & 137 & 38.5 & 219 & 61.5 & 1.0 & \\
\hline Females & 22 & 51.2 & 21 & 48.8 & 0.60 & $0.30-1.18$ \\
\hline \multicolumn{7}{|l|}{ Marital status } \\
\hline Single $e^{a}$ & 97 & 36.5 & 169 & 63.5 & 1.0 & \\
\hline Married & 10 & 55.6 & 8 & 44.4 & 0.46 & $0.16-1.31$ \\
\hline Divorced or widowed & 52 & 45.2 & 63 & 54.8 & 0.70 & $0.44-1.11$ \\
\hline \multicolumn{7}{|l|}{ Education level } \\
\hline Secondary school ${ }^{\mathrm{a}}$ & 23 & 65.7 & 12 & 34.3 & 1.0 & \\
\hline Intermediate school & 39 & 39.4 & 60 & 60.6 & 2.95 & $1.23-7.16^{*}$ \\
\hline Primary school & 55 & 40.7 & 80 & 59.3 & 2.79 & $1.20-6.54^{*}$ \\
\hline Illiterate or R\&W & 52 & 37.1 & 88 & 62.9 & 3.24 & $1.40-7.60^{*}$ \\
\hline \multicolumn{7}{|l|}{ Work status } \\
\hline Not working ${ }^{\mathrm{a}}$ & 136 & 39.0 & 213 & 61.0 & 1.0 & \\
\hline Working & 8 & 80.0 & 2 & 20.0 & 0.16 & $0.02-0.83^{*}$ \\
\hline Retired & 15 & 50.0 & 15 & 50.0 & 0.64 & $0.28-1.43$ \\
\hline \multicolumn{7}{|l|}{ Housing } \\
\hline Rented $^{\mathrm{a}}$ & 44 & 43.1 & 58 & 56.9 & 1.0 & \\
\hline Owned & 115 & 38.7 & 182 & 61.3 & 1.20 & $0.74-1.94$ \\
\hline \multicolumn{7}{|l|}{ Private income } \\
\hline Yes $^{\mathrm{a}}$ & 13 & 59.1 & 9 & 40.9 & 1.0 & \\
\hline No & 146 & 38.7 & 231 & 61.3 & 2.29 & $0.89-5.47$ \\
\hline \multicolumn{7}{|l|}{ Smoking status } \\
\hline Current smoker ${ }^{\mathrm{a}}$ & 67 & 39.6 & 102 & 60.4 & 1.0 & \\
\hline Ex-smoker & 63 & 42.3 & 86 & 57.7 & 0.90 & $0.56-1.44$ \\
\hline Non-smoker & 29 & 35.8 & 52 & 64.2 & 1.18 & $0.66-2.12$ \\
\hline \multicolumn{7}{|l|}{ History of drug addiction } \\
\hline$Y_{e s}^{a}$ & 99 & 41.7 & 141 & 58.8 & 1.0 & \\
\hline No & 60 & 37.4 & $\underline{99}$ & 62.6 & 1.16 & $0.75-1.78$ \\
\hline
\end{tabular}




\begin{tabular}{|c|c|c|c|c|c|c|}
\hline \multirow[t]{3}{*}{ Determinant } & \multicolumn{4}{|c|}{ Duration of hospital stay } & \multirow[t]{3}{*}{ Crude OR } & \multirow[t]{3}{*}{$95 \% \mathrm{Cl}$} \\
\hline & \multicolumn{2}{|c|}{$\begin{array}{l}\leq 2 \text { years } \\
(n=214)\end{array}$} & \multicolumn{2}{|c|}{$\begin{array}{l}>2 \text { years } \\
(n=216)\end{array}$} & & \\
\hline & No. & $\%$ & No. & $\%$ & & \\
\hline \multicolumn{7}{|l|}{ Reason for long hospitalization } \\
\hline Orders from high-ranking officials $\mathrm{s}^{\mathrm{a}, \mathrm{b}}$ & 34 & 52.3 & 31 & 47.7 & 1.0 & \\
\hline Family refused to take patient home & 101 & 35.2 & 186 & 64.8 & 2.02 & $1.13-3.60^{*}$ \\
\hline No family care & 24 & 51.1 & 23 & 48.9 & 1.05 & $0.46-2.39$ \\
\hline \multicolumn{7}{|l|}{ Diagnosis } \\
\hline Personality disorder ${ }^{\mathrm{a}}$ & 9 & 69.2 & 4 & 30.8 & 1.0 & \\
\hline Schizophrenia & 126 & 40.9 & 182 & 59.1 & 3.25 & $0.89-12.84$ \\
\hline Mental retardation & 11 & 44.0 & 14 & 56.0 & 2.86 & $0.57-15.17$ \\
\hline Schizophrenia + mental retardation & 9 & 20.0 & 36 & 80.0 & 9.00 & $1.90-46.22^{*}$ \\
\hline Epilepsy + other disease & 4 & 50.0 & 4 & 50.0 & 2.25 & $0.26-20.99$ \\
\hline \multicolumn{7}{|l|}{ Co-morbid disease } \\
\hline No & 133 & 43.6 & 172 & 46.4 & 1.0 & \\
\hline Yes & 26 & 27.7 & 68 & 72.3 & 2.02 & $1.19-3.46^{*}$ \\
\hline
\end{tabular}

${ }^{a}$ Reference category. ${ }^{b}$ Generally, at the request of patient's close relatives.

* Statistically significant.

$O R=$ odds ratio; $C I=$ confidence interval.

bonds had been cut [16]. However, in our study, we found no association between lack of work and long hospital stay.

In the current study, we found no association between sex and length of hospital stay and this was consistent with the findings of Taiwo et al. in $\mathrm{Ni}$ geria [17].

A comparison between our findings and those described for some British psychiatric hospitals in the TAPS project is worth mentioning [18]. In both studies around $90 \%$ of the sample was diagnosed with schizophrenia. Van Os and Kapur noted that schizophrenia was the most commonly reported mental disorder worldwide [19]. In a Brazilian study, diagnosis of schizophrenia and mental retardation were almost equally distributed, and together accounted for

\begin{tabular}{|c|c|c|}
\hline Variable & Adjusted OR & $95 \% \mathrm{Cl}$ \\
\hline \multicolumn{3}{|l|}{ Education level } \\
\hline Secondary school $(n=38)^{\mathrm{a}}$ & 1.0 & \\
\hline Intermediate school $(n=104)$ & 2.96 & $1.41-10.03^{*}$ \\
\hline Primary school $(n=143)$ & 1.55 & $1.16-8.13^{*}$ \\
\hline Illiterate or R\&W $(n=145)$ & 4.25 & $1.61-8.11^{*}$ \\
\hline \multicolumn{3}{|l|}{ Diagnosis } \\
\hline Personality disorder $(n=14)^{\mathrm{a}}$ & 1.0 & \\
\hline Schizophrenia $(n=382)$ & 1.78 & $0.74-7.56$ \\
\hline Mental Retardation $(n=26)$ & 2.09 & $0.60-10.14$ \\
\hline Schizophrenia + mental retardation $(n=44)$ & 7.02 & $1.95-33.12^{*}$ \\
\hline Epilepsy + other diseases $(n=8)$ & 2.40 & $0.40-17.55$ \\
\hline \multicolumn{3}{|l|}{ Co-morbid disease } \\
\hline No $(n=335)^{\mathrm{a}}$ & 1.0 & \\
\hline Yes $(n=95)$ & 2.18 & $1.47-4.13^{*}$ \\
\hline
\end{tabular}

Patient's age and reason for long hospitalization were removed from the final logistic regression model. a Reference category.

*Statistically significant.

$O R=$ odds ratio; $C l=$ confidence interval $R \& W=$ just able to read and write. 
$90 \%$ of all diagnoses [16]. Historical issues leading to the creation of health policies in these 2 countries along with the disparity in the availability of alternative resources for these patients could explain some of these differences.

Cattapan-Ludewig et al. reported that persons with serious mental illness, especially schizophrenia, smoke at much higher rates than those without schizophrenia [20], and patients with schizophrenia have a harder time quitting smoking. Our observations agreed with this: $42.9 \%$ of schizophrenic patients were current smokers and $40.8 \%$ were ex-smokers. This compares with $37.5 \%$ and $16.7 \%$ respectively for nonschizophrenic patients.

Certain thinking patterns are affected in schizophrenia including sustained attention, focused attention, working memory, short-term memory, recognition memory and even processes that are preattentive (e.g. reflexes) [20]. Some studies have suggested that there may be improvements in these areas after treatment with nicotine $[21-23]$. So, it may be that nicotine is used as a "selfmedication" strategy by those with schizophrenia to improve these difficulties as well as the side-effects of antipsychotic medications (e.g. extrapyramidal effects).
There is greater co-morbidity, or cooccurrence, of substance dependence in individuals who have mental illness, especially schizophrenia, compared with individuals without any mental disorder. This indicates either a shared neurobiological basis for both, or an interaction of effects at some level [24]. We also noted a statistically significant association between schizophrenia and drug addiction.

In the current study, presence of co-morbid illness was statistically significantly associated with longer hospital stay. Similar findings have been reported by other researchers [25].

For long-stay patients, it seems clear that the greatest influence on how long they stay in hospital is where they are discharged to. In a national sample survey of 15 mental hospitals in England and Wales, about one-third of the patients needed further medical care, one-third were suitable for discharge into the community, and the remaining one-third, because of multiple handicaps including physical disability and mental retardation, were in hospital simply because no other agency would accept them [9]. In our study, long hospital stay was mainly due to the refusal of the family to take patients back into the home.

One of the strengths of the current study was the relatively large number of patient records examined, which allowed for division into sub-groups.

The study was, however, not without limitations. We did not have enough resources to look into clinical and social data in detail, e.g. previous treatment, family support, social functioning on admission and discharge, etc. These could be important factors influencing the duration of hospital stay. Further studies into these areas would be valuable. In addition, the study included patients from only one institution (although it did accept patients from throughout Saudi Arabia). Thus, the results of this study should be generalized to other geographic regions with caution.

Despite these limitations, this study on the characteristics of the long-stay population of a psychiatric hospital stands out as an important contribution towards improving the conditions for the health treatment of this population for at least two reasons: it allows for managing interventions concerning specific aspects, and it establishes standard measurements for this population so that the impact of future interventions can be estimated.

\section{References}

1. Goldman HH, Manderscheid RW. The epidemiology of psychiatric disability. In: Meyerson AT, Fine T, eds. Psychiatric disability: clinical, legal, and administrative dimensions. Washington DC, American Psychiatric Association Press, 1987:13-21.

2. Curson DA, Panetelis C, Ward J. Institutionalisation and schizophrenia 30 years on. Clinical poverty and the social environment in three British mental hospitals in 1960 compared with a fourth in 1960. British Journal of Psychiatry, 1992, 160:230-241.

3. Davidge M et al. Survey of English mental illness hospitals. Birmingham, England, Health Service Management Centre, 1993.

4. Manderschied RW, Sonnenschein MA, eds. Mental health, United States. Rockville, Maryland, Department of Health and Human Services, 1994.

5. Tantum D. Alternatives to psychiatric hospitalisation. British Journal of Psychiatry, 1985, 146:1-4.

6. Rothbard A et al. Service utilization and cost of community care for discharged state hospital patients: a 3-year follow-up study. American Journal of Psychiatry, 1999, 156:920-927.

7. Rothbard AB et al. Service use and cost in 2002 among clients in community settings who were discharged from a state hospital in 1989. Psychiatric Services, 2007, 58(12):1570-1576.
8. Hallam A et al. The costs of accommodation and care. Community provision for former long-stay psychiatric hospital patients. European Archives of Psychiatry \& Clinical Neurosciences, 1994, 243:304-310.

9. Mann SA, Cree W. "New" long-stay psychiatric patients: a national sample survey of fifteen mental hospitals in England and Wales 1972/3. Psychological Medicine, 1976, 6:603-616.

10. El-Hazmi MAF. Early recognition and intervention for prevention of disability and its complications. Eastern Mediterranean Health Journal, 1997, 3(1):154-161.

11. El-Hazmi MAF et al. Prevalence of mental retardation among children in Saudi Arabia. Eastern Mediterranean Health Journal, 2003, 9(1/2):6-11.

12. Abdul-Salam A et al. Pattern of disability among patients ati tending Taif rehabilitation center, Saudi Arabia. Disabililty and Rehabilitaion, 2008, 30(11):884-890.

13. Driller E, Pritzbuer EV, Pfaff H. Versorgungsbedarf und Behinderung - Taugt die amtliche Schwerbehindertenstatistik fur die Bedarfsanalyse? [Care required by disabled persons: are official severe disability statistics good enough for requirement analyses?] Gesundheitswesen, 2004, 66(5):319-325. 
14. Gath DH, Hassall C, Cross KW. Whither psychiatric day care? A study of day patients in Birmingham. British Medical Journal, 1973, 1:94-98.

15. Diagnostic and statistical manual of mental disorders (DSM IV), 4th ed. Washington DC, American Psychiatric Association, 1994.

16. Fleck MPA et al. Long-stay patients in a psychiatric hospital in Southern Brazil. Revista Saúde Pública, 2007, 41(1):124-130.

17. Taiwo $\mathrm{H}$ et al. Long stay patients in a psychiatric hospital in Lagos, Nigeria. African Journal of Psychiatry, 2008, 11:128-132

18. O'Driscoll $\mathrm{C}$ et al. The TAPS project 10: the long-stay populations of Friern and Claybury hospitals. The baseline survey. British Journal of Psychiatry, 1993, 162(19 Suppl.):30-35.

19. Van Os J, Kapur S. Schizophrenia. Lancet, 2009, 374(9690):635645.

20. Cattapan-Ludewig K et al. Warum rauchen Schizophreniepatienten? [Why do schizophrenics smoke?]. Nervenarzt, 2005 76:287-294.
21. Harris JG et al. Effects of nicotine on cognitive deficits in schizophrenia. Neuropsychopharmacology, 2004, 29(7):1378-1385.

22. Lyon ER. A Review of the effects of nicotine on schizophrenia and antipsychotic medications. Psychiatric Services, 1999, 50(10):1346-1350,

23. C Smith RC et al. Effects of cigarette smoking and nicotine nasal spray on psychiatric symptoms and cognition in schizophrenia. Neuropsychopharmacology, 2002, 27(3):479-497.

24. Ridgely MS et al. Chronically mentally ill young adults with substance abuse problems: a review of research, treatment, and training issues. Baltimore, Maryland, University of Maryland, School of Medicine, Mental Health Services Research Center, 1987.

25. Wancataa J et al. Does psychiatric comorbidity increase the length of stay in general hospitals? Abstracts of the Academy for Health Services Research and Health Policy Meeting, 2002, 23(1):8-14.

\section{Improving quality and human rights in mental health}

All over the world, people with mental and intellectual disabilities and substance use disorders are subject to poor quality care and violations to their basic rights. These conditions are also highly stigmatised resulting in social exclusion and marginalization of affected people. Health settings are not free of stigma and discrimination towards people with mental and intellectual disabilities and substance use disorders. In fact, some of the worst violations of rights and most discriminative practices occur within the health care facilities.

The United Nations Convention on the Rights of Persons with Disabilities is the basis for human rights standards that must be respected, protected and fulfilled in facilities. The Convention was endorsed on 3 May 2008, and 16 of the 22 Member States of the Eastern Mediterranean Region have ratified it.

Translating the provisions of the Convention on the Rights of Persons with Disabilities into action, WHO has developed the QualityRights Toolkit to support countries in assessing their mental health and social care facilities in order to improve the quality of services with observance the rights of patients.

The WHO Regional Office, as a joint initiative between the departments of health systems and noncommunicable diseases and mental health with support from WHO headquarters, conducted a training of trainer's workshop in December 2012. The workshop was attended by mental health and human rights focal points from selected Member States and country offices of WHO. The objectives of the workshop were to familiarize the participants with the QualityRights project, the Toolkit and develop an action plan for implementing the project in respective countries.

Further information about the work of WHO in the Region on mental health and the rights of people with disabilities can be found at: www.emro.who.int/entity/mental-health/ 